\title{
Regivärsist üldse ja vepsa regivärsist eriti
}

Avaldatud: Keel ja Kirjandus 1991, vol 34, nr 8, lk 452-458

Juba 1981. a. ilmus Tartu Ülikooli toimetiste 587. vihik ("Studia metrica et poetica"), mille esimeseks artikliks on Paul Alvre "Vepsa regivärsi mõistatus". ${ }^{1}$ Sain selle toimetiste numbri mõnevõrra hiljem ja lugema juhtusin seda veelgi hiljem. Kõrvuti põhiteesiga, et vepslastel esineb või on esinenud nn. regivärsilist rahvalaulu, kohtab artiklis väidet: "Ainult tugev luuletraditsioon võib suuremate keeleliste mullistuste korral (nagu seda on sise- ja lõpukadu) päästa rahvalaulu hävingust, sest kõik laulud tuleb vastavalt uutele keelereeglitele luua otsekui uuesti. Nii on toimitud eesti regilauludega, ja seda ilmselt pika ajaloo vältel mitmelgi korral. Algsete rõhusuhete segipaiskamine on avanud samas tee skandeerimisele, kus rõhutut silpi võib markeerida värsijala tõus, ja rõhulist langus."2 Lühidalt öeldes väidab P. Alvre, et 1) eesti rahvalaulu (s.o. regivärssi) on aja jooksul sobitatud mitu korda uute keelereeglitega ja 2) et skansioon on hiline nähtus. P. Alvre viitab sise- ja lõpukaole, mis vepsa keeles olevat üldiselt "sama kui eesti keeles või soome edelamurdeis"3, ainult vepsa keeles on see toimunud "küllalt hilja". Millal just, seda autor ei täpsusta. Eesti keeles arvatakse lõpu- ja sisekadu olevat toimunud juba XIV sajandil. Ometi kohtame veel XIX-XX sajandil kirjapandud regivärssides nii lõpu- kui ka sisekaota vorme. Lööme lahti kas või antoloogia ja juba esimesest laulust leiame värsid:

Üks on õunapuu mäella, üks on oksa õunapuussa, üks on õile oksa päälla, üks on õuna ôlle päälla....

või:

Luogelekse linnukene, luogelekse, lendelekse.... ${ }^{4}$ 
Lisanäiteid võib tuua ohtrasti igaüks, kes regilaulu vähegi tunneb. Millal ja mil moel on need laulud sobitatud muutunud keelereeglitega? Ja missugune oleks nende laulude n.-ö. muutuste-eelne kuju? Need küsimused jäävad vastamata. Just regivärsi vorm - mitte abstraktne luuletraditsioon - on säilitanud regilaulu arhailise keelekuju. Ja kui seda arhailist laulu hakatigi sobitama muutunud keelega, siis ei olnud tulemuseks mitte regivärss, vaid kas siirdevormiline laul või uuem, lõppriimiline rahvalaul. Hea näide on siin kas või muistne «Loomislaul», mille viimast arenguetappi on jälginud I. Rüütel. ${ }^{5}$

Muutused keeles, kõnekeele ja regivärsikeele eristumine tõi tegelikult kaasa regilaulude hääbumise ning lõpuks nende kadumise. ${ }^{6}$ Sellel - nagu viidatud artiklitestki näha - oli küll muidki põhjusi, kuigi keele osa oli kahtlemata oluline. Ilmekalt nähtub see muide tekkeliselt viimasest regilaulude rühmast, nimelt nekrutilauludest, mis on pealegi dateeritavad. Nekrutivõtmine kehtestati Eestis a. 1797 (kestis aastani 1874). Niisiis on nekrutilaulud tekkinud pärast aastat 1797. Nekrutilauludes on tunda regilaulu vormi murenemist, näiteks:

Üks oli vennake minule - seegi sõlmiti sõdaje, värvuke Vene väessa.

Mingu katki purjepaelad lagunegu laevamastid

või:

minu venda viiessa. Kasvas kui kala meressa, vesinaati allikassesealt ta üles otsiti, ikka sõtta sõlmiti. ${ }^{7}$

Sellest hoolimata arvestatakse nekrutilaulud liigina ikkagi regilaulude hulka. P. Alvre väide regilaulu $\mathrm{k}$ o $\mathrm{r} \mathrm{d} \mathrm{u} \mathrm{v} \mathrm{a} \mathrm{s} \mathrm{t} \mathrm{sobitumisest} \mathrm{keelega} \mathrm{jääb} \mathrm{katteta.}$ Vaadeldes meie rahvalaulu tervikuna, võib minu arvates rääkida ainult kahest n.-ö. taasloomisest. Esimene oli siis, kui muistsest ürglaulust loodi regivärsiline rahvalaul, ja teine siis, kui regivärsist loodi siirdevormiline rahvalaul. Viimane on selgesti fikseeritud ja osalt isegi dateeritav. Esimene on mõistagi oletuslik, kuigi väga tõenäone.

Muidugi on eriprobleemiks meie laulupärimuse pidevus. Siingi näikse teadlaste seas valitsevat kaks vastandlikku seisukohta, mida alati ei ole küll teadvustatud. Soome koolkonna esindajate arvates õpiti laulud pähe sõna-sõnalt nagu vanasõnad, mõistatused jt. lühifolkloori liigid. K. Krohn analüüsib oma käsiraamatus ${ }^{8}$ üksikasialikult põhjusi, miks tekivad muutused esialgses laulutekstis, s.t. ta eeldab algse, tervikliku teksti omandamist lauliku poolt. Sellestsamast lähtub oma eksperimentaalsete uurimuste puhul ka W. Anderson. ${ }^{9}$ Ent mida enam olen õppinud tundma eesti regilaulu, seda enam on minus kinnistunud veendumus, et laulik ei õppinud mitte laule, vaid omandas M. Kuusi väljendit kasutades - regivärsi koodi ehk reeglistiku. Mõistagi oli see 
praktikast, kogemuslikkusest lähtuv, mitte teoreetilise arutelu vili. Omandatud koodi, teada oleva süžee (lüroeepilise laulu puhul), funktsionaalse tingituse (töö-, tavandilaulu puhul) või teema (lüürilise laulu puhul) ning meeldejäänud värsside abil taaslõi laulik soovitud laulu. Küllap võib seda nimetada ka improviseerimiseks. See seletaks meie regilaulu üpris kireva koostise (rohked paralleeltüübid, lähedased redaktsioonid ja erinevad variandid). Mõistagi ei saa seda seletust rakendada kõikide laulikute puhul. Küllap on siin igasuguseid vahenähtusi. Oli ehk selliseidki laulikuid, kes laulu sõna-sõnalt pähe õppisid. Ehk aitab siia selgust tuua Lauri Harvilahti väitekiri. Siinses seoses on see üksnes kõrvalepõige.

Kuidas on lood väitega skansiooni hilisuse kohta? Sellele vastamiseks on meil kasutada W. Andersoni ja A. V. Kõrvi uurimused. ${ }^{10}$ W. Anderson seabki oma uurimuse üheks ülesandeks väüa selgitada, kas algupärasem on skandeerimine või mitteskandeerimine. H. Paukson teadupärast leidis lauljatel nii skansiooni kui ka skansiooni vältimist. ${ }^{11} \mathrm{~W}$. Andersoni see deskriptsioon ei rahuldanud. Ta järeldab: "Meie statistika tõestab, et Kolga-Jaani laulutekstid kõikjal eeldavad ja kajastavad skansiooni, ükskõik kas neid tegelikult esitati skandeerides või mitte, ja et sellepärast skandeeriv esitus on algupärasem."12 Ja lisab: "Eestis praegu paljudes kohtades tabatav skansioonita ettekanne ei ole relikt tollest hüpoteetilisest muinasajast, vaid novum, niisiis mitte primaarne, vaid sekundaarne nähtus."13 Kui W. Andersoni väitele eelneb 122 lehekülge analüüsitud värsiainest, siis P. Alvre väide on paljasõnaline. Möönan, et usun pigem W. Andersoni - kuni tema tõestusi ei kummutata. P. Alvre puhul peab aga küsima, kust on võetud see enesekindel väide skansiooni ja rõhu suhete segipaiskamise seostest? Skansiooni äge eitaja oli Juhan Zeiger, üksvahe ka H. Tampere, kuid nemad lähtusid eeskätt rahvaviisidest, täpsemalt - rahvaviiside kirjapanekutest. Võimalik muidugi, et olen midagi või kedagi kahe silma vahele jätnud. Aga tõenäolisem on, et see on P. Alvre enese n.-ö. avastus. Kui kõrvalväited nii rappa lähevad, siis tärkab kahtlus ka peaväite suhtes. Kuidas on ikkagi lood regilauludega Vepsas? Selleks vaatleme regivärssi ülepea.

Viimasel ajal on eriti Soomes taas rõõmustavalt kasvanud huvi regivärsilise resp. kalevalamõõdulise rahvalaulu vastu, osalt muidugi "Kalevala" juubeliks valmistumsiel. Jätame kõrvale klassikud nagu K. Krohn, A. Ahlqvist jt. Jälgime, kuidas tänapäevased uurijad teavad või mõistavad regilaulu. Outi Lehtipuro kirjutab kalevalamõõduliste laulude tuntusest soome ja karjala keele alal ning Eestis. ${ }^{14}$ Lehekülg hiljem lisab ta ka Ingerimaa. P. Leino märgib: "Läänemeresoome rahvastest on lisaks soomlastele ja karjalastele vähemalt ingerlastel, vadjalastel ja eestlastel olnud rahvalauludel meetrum, mis on vaieldamatult sama algupära kui kalevalameetrum. Päris ühesugune see eri keele- ja laulualadel tõepoolest ei olnud, aga ühtelangevused on palju suuremad kui erisused. 
Üldiselt oletatakse, et see laulumeetrum on sündinud ehk 2500 aastat tagasi, võimalik, et balti rahvastelt saadud mõjutuste ja oma pärimuste kohtumisel." 15

Suures üldesituses kalevalamõõdulise rahvalaulu sünni kohta märgib M. Kuusi: "Kalevalamõõdulist luulet on kohatud läänemeresoome läänepoolseil rahvail - eestlastel, liivlastel, vadjalastel, soomlastel ja neile lähemal asunud karjalastel -, kuid mitte laplastel, vepslastel ja idapoolsematel karjalastel." ${ }^{\prime 6}$ Hilisemas laulude käsitelus autor paraku ei viita ühelegi liivi laulule.

Liivi rahvalaulud avaldas O. Loorits a. 1936. Kogumikus on 645 teksti. Kahjuks ei leidu nende seas ühtegi, mida ilma suurte reservatsioonideta saaks seostada kalevalavärsiga. Ütleb ju koostajagi teose eessõnas, et "algupäraseid laule on nende seas harva leida ja vanad, soome-eesti laulukultuuri ja laulurepertuaariga ühised jooned pole vahetult üldsegi säilinud. Kõige huvitavam on võib-olla ebateadlik allitereeruva algriimi taotlus". ${ }^{17}$ Tõepoolest, alliteratsiooni ja assonantsi liivi lauludes leidub, kuid juhusliku, pigem keeles loomulikult esineva kui kunstikavatsusliku nähtusena. Kui pearõhk on esimesel silbil, tundub ju juhuslikki alliteratsioon tähenduslikuna. Ka parallelism - või täpsemalt - parallelismi meenutavat kordust kohtab liivi lauludes siin-seal, kuid taas mitte laulu läbiva struktuurielemendina, vaid ajuti kasutatava kunstilise võttena. Trohheiline liivi laul küll on, aga mitte alati, neljajalaline, ja kui on, siis vahelduvad katalektilised ja akatalektilised värsid. Näiteks:

lõlis iza, lõliz puoga,

lõlist kakši pälkamiest.

Peaasi, liivi laulus ei ole jälgegi kvantiteerivast rütmist. Muide, 15 aastat hiljem osutab M. Kuusi, et ka liivi vanasõnades näib klassikaline kalevalamõõt täiesti puuduvat. ${ }^{18}$ Kas on mõeldav, et liivlased on regivärsi jäägitult unustanud, nii et selle olemasolust pole isegi relikte? See on äärmiselt ebatõenäoline. Näiteks vadjalased ei elanud ju kuidagi soodsamates oludes: samasugune hajaasustus, läbisegi võõrastega, kellel hoopis teistsugune laulukultuur. Ometi pani P. Ariste vadjalastelt kirja ehtsaid regivärsse kuni lõpuni (mõtlen siin vadjalaste hääbumist). Ehk oleme tõele lähemal, kui oletame, et liivlastel pole olnudki regilaulu selle klassikalisel kujul. Lingvistid väidavad, et liivlased olid esimesed, kes hargnesid läänemeresoome algkeelest. Võib arvata, et see lahknemine toimus enne regilaulu tekkimist. Liivlaste laul jäi regivärsieelsesse staadiumi. Sellegi alg- või ürglaulu on varjutanud hilisemad laululaenud nii naabritelt kui ka kirjandusest.

Kuidas on lugu vepsa regivärsiga? Esitanud ohtralt näiteid alliteratsiooni ja parallelismi esinemise kohta, kinnitab P. Alvre: "Vana vepsa regivärss on küll tänapäevaks suurelt osalt taandunud, kuid selle elemente kuni üksikvärssideni välja on üle kandunud moodsasse rahvalauluvormi - tšastuškadesse. 
Nende ligem analüüs ja kõrvutamine pikemate rahvalauludega aitab edaspidi kindlasti tungida sügavamini vepsa regivärsi omapärasse. Kuid juba praegugi on selge, et nii neljajalaline trohheus oma allvariantidega kui ka hääliku- ja mõttekordus pole vepslastel mingid juhuslikud elemendid, vaid nad on iidne pärand läänemeresoome rahvaste regivärsikultuuri ühisajast. Vepsa regivärsi deformeerumisele on kaasa aidanud keeles toimunud suured häälikulised murrangud (sise- ja lõpukadu). Varasemate pikemate sõnavormide rekonstrueerimine lubab sageli siiski taastada korrapärase värsimõõdu. Ilma lingvistiliste rekonstruktsioonivõteteta pole mõeldav ka eesti regivärsi kihistute uurimine ning nende kõrvutamine arhailisema soome ja karjala esinemusega. Vepsa regivärsiprobleemistik aitab mõneti paremini mõista ka eesti rahvalaulu korduva taassünni protsessi, sealhulgas ka üleminekut skandeerimisele."19 Toimetaja lisab joonealuses märkuses: "Idee regivärsi korduvast ümbersõnastamisest viib lõppkokkuvõttes regivärsi (praeguse) meetrilise heterogeensuse tunnustamiseni ja selle dünaamilise tüpoloogia juurde."20

Kahtlemata tunnevad ja kasutavad vepslased algriimi. Kuivõrd nendegi keeles on pearõhk sõna esimesel silbil, on see loomulik. Hoopis kidasem on lugu parallelismiga. Enamik P. Alvre esitatud näiteid põhineb sõnakordusel. Sõnakordus ei ole mõttekordus. Aga parallelismi siiski leidub. Kuid algriim ja parallelism ei anna veel regivärssi. Tõsi, P. Alvre tsiteeritud lauluaines on vana, see on "Tähemõrsja" versioon, mis peaks ulatuma tagasi üpris kaugesse minevikku. Kuid lauluaines - praegusel juhul vana müüditeema - ja laulu vorm ei ole üheselt vastavad. Heaks näiteks eesti rahvaluulest võib olla kas või «Lunastatav neiu», mida tuntakse nii regivärsilise lauluna ${ }^{21}$ kui ka uuema, siirdevormilise lauluna ${ }^{22}$. Kuid seegi on ainult lisaargument. Oluline on rõhutada: regivärss tähendab kindlat värsistruktuuri (normaalselt kaheksasilbiline, kvantiteeriva trohheilise rütmiga, kindlate reeglitega). Reeglitest on olulistena esile tõstetud järgmisi: rõhuline pikk silp esineb ainult värsijala tõusus, rõhuline lühike silp värsijala languses, esimene värsijalg on vabalt täidetav, värss ei lõpe ühesilbilise sõnaga, neljasilbiline sõna on eelistatavalt värsi lõpul või ka värsi algul, mitte iialgi aga värsi keskel; kui esimeses värsijalas on kolm või neli silpi, ei tohi need kuuluda ühte sõnasse.

P. Alvre artiklis esitatud näiteid on raske sobitada nende reeglitega. P. Alvre soovitab rekonstrueerida vanemaid vorme. ${ }^{23}$ Näiteks värss joksin, joksin jogut mö kõlanud enne: ...jogut möto. Kuid me peaksime lisama ka sõnale jogut endise partitiivi lõpu (t)a - ja saame: joksin, joksin joguta möto, niisiis üheksasilbilise värsi, mis kuidagi ei vasta regivärsi reeglitele. Samuti jääb arusaamatuks, miks värsis pitkikš üikš kuštmaha rekonstrueeritakse ainult viimased sõnad pitkikš üikši kuštamahan (ilmselt selleks, et saada kaheksa silpi). Ometi tulnuks värsist korrektsel rekonstrueerimisel üheksasilbiline: pitkikši üikši kuštamahan! 
On ju selge, et rekonstrueerida tuleb kogu tekst, mitte suvalised värsid või sõnad. Näites on 28 värssi, neist viiesilbilisi - 1, kuuesilbilisi - 2, seitsmesilbilisi - 11, kaheksasilbilisi - 6, üheksasilbilisi - 6, kümnesilbilisi - 1 ja üheteistkümnesilbilisi - 1. Kui rekonstrueerimisel iga värss pikeneb silbi võrra, siis jääb ikkagi osa värsse lühemaks kui kaheksa silpi, osa aga paisub pikemaks kui kaheksa silpi. Kas rekonstrueeritud või rekonstrueerimata - regivärsi alla seda esitatud laulunäidet ikkagi ei sobita (juba täiesti naeruväärne on analüüs värsside kaupa, et vaat - see ja see värss on täiesti regivärsipärane). Ja ega siis regivärsilisus ei tee rahvalaulu veel oluliseks või tähenduslikuks. Tõeliseks avastuseks oleks ju regivärsieelse rahvalaulu avastamine!

Näib, et vepsa keele lahknemine algläänemeresoome keelekujust ja sellele järgnev lühenemine toimus enne regivärsi tekkimist. On muide iseloomulik, et keeltes kus puudub regivärss, ei ole ka astmevaheldust. ${ }^{24}$ Mõistagi on astmevahelduseta keeltes silbi pikkuse-lühiduse määramine ja sellest johtuva kvantiteeriva värsimõõdu loomine keerukam. Ja seda tahangi rõhutada - olgu silpide arvuga kuidas tahes, kvantiteedireeglitele nad ei vasta. Aga need on ju regivärsi aluseks. Niisiis, kas pole lihtsam ja kasutada olnud näitematerjalile vastavam, kui väidame, et vepslased ei jõudnud regivärsini, et vepslased kasutasid nn. regivärsieelset laulu, mis muidugi viljeles algriimi ja sõnakordusel põhinevat parallelismi. See alglaul oli müüdieepika ja muude rituaaltekstide esitamiskood. Viitan taas M. Kuusile, kes arvab selle alglaulu (s.o. regivärsi-eelse laulu) jälgi leidvat lapi ja vepsa rahvalauludest. ${ }^{25}$ Mitmesugustel põhjustel - algläänemeresoomekeelest lahknemise aeg, asumine perifeerias, vähesed kontaktid keelehõimlastega -, ei jõudnud regivärss vepslasteni, vaid nad säilitasid oma muistse laulukuju kuni selle hääbumiseni ja kokkusulamiseni XIX sajandil tšastuška-traditsiooniga. Kahtlemata on vepsa rahvalaul regivärsi uurijale äärmiselt oluline, kuivõrd see on ainuke autentne materjal, mis aitab selgitada olukorda enne regilaulu tekkimist. Sestap on kahetsetav, et vepsa ainese kogumisega nii tagasihoidlikult tegeldakse (võinuks ju loota, et pärast P. Ariste lahkumist mõni TÜ soome-ugri keelte professoritest võtaks oma hoolde vepsa keele- ja rahvaluuleainese kogumise, eriti kui arvestada, et vepsa keelt on läänemeresoome keeltest kõige vähem jäädvustatud).

Kuid pöördume tagasi regivärsi poole ja alustame skansioonist. Skansioonist on põhjust kõnelda värsside puhul mis sisaldavad kolmesilbilisi sõnu (näit. vihule', vihu'le, virved jne.). Selliseid, s.o. kolmesilbilisi sõnu oli juba läänemeresoome algkeeles. Kolmesilbilisteks muutuvad ka kahesilbiliste tüvede muutevormid. Skansioon on täiesti reeglipärane soome ja karjala rahvalaulus. Kolmesilbilisi sõnu sisaldava värsi märkimiseks kasutavad soomlased nimetust murrelmasäe (murdvärss, rõhulibistusega värss). Klassikalises regivärsis on seesugustel värssidel oma kindel määr. M. Kuusi märgib, et parimatel karjala-ingeri 
laulikutel on puhttrohheilisi ja murdvärsse enam-vähem ühepalju. ${ }^{26}$ Normiks on peetud, et värssidest kolmandik oleksid murdvärsid. Selleni küünivad ka Virumaa laulud. ${ }^{27}$ Karksis seevastu on nende protsent ainult 23, Kolga-Jaanis $18,8^{28}$ ja Põlvas ainult $12 \%{ }^{29}$. Võib konstateerida: Lõuna-Eestis on rõhulibistusega värsse märgatavalt vähem ja kvantiteedireegleid ei jälgita nii hoolega kui Põhja-Eestis. Eksitakse eriti reegli vastu, et lühike pearõhuline silp peab olema värsijala languses (on tõusus). Palju harvemini eksitakse selle reegli vastu, et pearõhuline pikk silp ei tohi olla värsijala languses. Kuidas seda seletada? K. Krohn ja teisedki soome õpetlased peavad seda hiliseks nähtuseks, aktsentueeriva rütmi taotluseks, algse kvantiteeriva rütmi ja seega ka regivärsi taandumisnähtuseks. Teiselt poolt on H. Paukson ja O. Loorits (hiljem ka H. Tampere) oletanud selles nähtuses arhailisemat astet, n.-ö. regivärsieelset staadiumi. Nagu juba nägime, astus H. Pauksoni vastu välja W. Anderson. Kuid W. Anderson uuris Kolga-Jaani, s.o. Põhja-Eesti, ehkki selle lõunapoolse osa rahvalaule. Niisiis kehtib W. Andersoni väide ikka ja eelkõige Põhja-Eesti kohta. Aga Lõuna-Eesti rahvalaul?

Võtaksin appi Pentti Leino särava uurimuse «Kalevalamitan ongelma». Seal tõdeb autor, et teoreetiliselt saab esitada meetrilise opositsiooni ilmnemisest neli erinevat versiooni: see võib esineda 1) meetriliselt tugeva ja nõrga silbi opositsioonina, 2) meetriliselt tugeva ja neutraalse silbi opositsioonina, 3) meetriliselt nõrga ja neutraalse silbi opositsioonina ja 4) meetriliselt tugeva ja nõrga silbi "polaarse" opositsioonina, kui juures on veel kolmas, meetriliselt neutraalne kategooria. ${ }^{30}$ Just neljas on regivärsiomane opositsioon. Muidugi küsitakse, miks regivärsis silbid jaotuvad kolme kategooriasse: meetriliselt tugevateks, nõrkadeks ja neutraalseteks. P. Leino kinnitab, et see on üldine meetriline omadus, mis kordub eri aegadel, eri keeltes ja eri meetrikates. Mõistagi on pikad pearõhulised silbid meetriliselt tugevad. Rõhutud silbid on neutraalsed. Kuid lühikesed pearõhulised silbid on meetriliselt nõrgad ja nimelt seepärast, et regivärss on - tüpoloogilise klassifikatsiooni järgi - lisaks aktsentueerivale ja kvantiteerivale ka süllaabiline. Välja arvatud vabalt täidetav esimene värsijalg, on silpide arv värsijalas määratud - nii värsijala tõusus kui ka languses saab olla ainult üks silp. Sellest johtub vajadus viia värsijala langusse ka pearõhulisi silpe - teisiti ei saaks kasutada kolmesilbilisi sõnu. Nii saidki meetriliselt nõrgaks lühikesed pearõhulised silbid. Toimus vastandus: pikad pearõhulised silbid kui meetriliselt tugevad ja lühikesed pearõhulised silbid kui meetriliselt nõrgad. Kõik muud silbid on meetriliselt neutraalsed, kasutatavad kord värsijala tõusus, kord värsijala languses. Oma uurimuse lõpul viitab P. Leino, et lõunaeesti värss näikse vastavat pigem teisele opositsioonile, nimelt meetriliselt tugeva ja neutraalse silbi vastandamisele, kui klassikalisele kalevalamõõdule ehk neljandale opositsioonile. ${ }^{31} \mathrm{P}$. Leino ütleb ebaselge olevat, 
kas Lõuna-Eesti laulud on liikunud olukorrast 4 olukorda 2 või vastupidi - on liikumas olukorrast 2 olukorda 4. Mõistagi peaksime küsimuse lahendama meie. Paraku ei ole meil regivärssi ja tema meetrumit peaaegu uuritud, või kui siis ainult juba olemasoleva statistika põhjal. Ka alljärgnev arutelu põhineb intuitsioonil ja lugemusel, mitte uuel statistikal.

Põhja- ja Lõuna-Eesti värsi erisusele olen juba viidanud. Kuid võrrelgem näiteks Saaremaa ja Lõuna-Eesti regivärssi. On selgesti tajutav Saaremaa regivärsi hiline, n.-ö. sekundaarne trohheilisus. Näiteid leiab igaüks ohtrasti "Vana Kandle" V köitest (Tallinn, 1985), aga eriti O. A. F. Mustoneni raamatukesest "Virolaisia kansanrunoja. Vihukene eesti rahva laulusid" (Helsinki, 1893). Murdvärsse on seal vähe, üldistunud on värsiskeemid 2222 või 224 (ka 44, 1124). Saaremaa regivärsiga võrreldes tundub Lõuna-Eesti regivärss tõesti vanamoodsem, arhailisem, reliktsem. Ühineksin pigem H. Pauksoni ja O. Looritsaga, kes asuvad seisukohal, et lõunaeesti värss esindab varasemat, primitiivsemat arenguastet ehk otse öeldes - regivärsieelset olukorda. Viimane termin pärineb minult, mitte eelmainitud auväärsetelt uurijatelt. Seda oletust toetab lingvistide arvamus, et lõunaeesti olevat liivi järel järgmine keel resp. hõimurühm, mis eraldus läänemeresoome algkeelest.

Sellest järeldub, et klassikalist regivärssi viljelesid ainult ümber Soome lahe elavad hõimud: soomlased, karjalased, isurid, vadjalased ja põhjaeestlased. Ilmselt olid sidemed üle Soome lahe tihedamad kui metsade ja soode taha. On ju veetee ühendavale osale rahvaste elus varemgi osutatud. Samuti tuleb arvestada üpriski vilgast laulude vahetust ümber Soome lahe. Sellele viitas juba K. Krohn, leides paljude "Kalevala" laulude kodu Eestist. Sellele osutab ka M. Kuusi uurimus "Maria Luukan laulut ja loitsut" (1983). R. Mirov on leidnud sel alal ühisjooni mängulauludes, Mare Kõiva loitsuluules ja siinkirjutaja kalendaarsetes lauludes. Ehk annab sellele küsimusele põhjaliku vastuse kunagi valmiv soome-eesti rahvalaulude konkordantsregister. Ent nüüdki tõdeb M. Kuusi: "Soome lahe äärne ühiskultuur on ulatunud tugevana Eesti põhjarannikule, eriti Kuusalusse, ja selle mõjutuse kaardistamine on esmajärgulise tähtsusega nii Eesti kui ka Ingeri ja Lõuna-Karjala rahvaluulekihistuste tunnistamiseks. Keeleanalüüsi vahenditega oleks võimalik osutada Eestist Lääne-Ingerisse levinud, võib-olla Eestis hiljem kadunudki laule (Kalervikko ja Lemmykäinen)."32

Ilmselt oli läänemeresoomlastel oma alg- või ürglaul, mis kasutas algriimi, kordust ja kordusel põhinevat parallelismi. Teatava pildi sellest ürglaulust annavad lapi ja karjala joiud. Sellest ürglaulust kujunes nähtavasti balti rahvaste mõjul - regivärss või n.-ö. algregivärss, milles oli kaheksasilbiline värss, ja sellest omakorda Soome lahe ümber asuvatel rahvastel klas s ik a line regilaul oma kvantiteedireeglitega. Kaugemal asuvad hõimud-vepsla- 
sed, lõunaeestlased, liivlased - ei jõudnudki klassikalise regivärsini. Liivlastel näikse olevat ununenud ka vana lauluaines. Vepslastel ja eriti lõunaeestlastel lauluaines säilis, kuid vorm ei küündinud regivärsini. Enne tulid juba muutused, mis tõid kaasa vana laulustiili unustusse vajumise. Meie ülesandeks peaks olema lõunaeesti, sealjuures eriti setu värsi uurimine ja selle stadiaalsuse lahendamine. Selge on see, et seejuures on eriti vaja viisiuurijate abi.

\section{Kommentaarid}

1 P. Alvre, Vepsa regivärsi mõistatus. Tartu Riikliku Ülikooli toimetised. Vihik 587. Tartu, 1981, lk. 3-12.

2 P. Alvre, Vepsa regivärsi mõistatus, lk. 6-7.

3 P. Alvre, Vepsa regivärsi mõistatus, lk. 6.

4 Eesti rahvalaulud I:1. Antoloogia. Tallinn, 1969, lk. 13 (laul nr. 1).

5 Vt. I. Rüütel, Muistne «Loomislaul» eesti uuemas rahvatraditsioonis. Paar sammukest VI. Tallinn, 1969, lk. 102-132.

6 Vt. lähemalt: T. Okko1a, Vanhan runolaulun häviämisestä Virossa. Suomi V: 5. Helsinki, 1923, lk. 211-247; U. Tedre, The change in Estonian folklore in the 19th century. Acta Universitatis Stockholmiensis. Studia Baltica Stockholmiensia 2. Stockholm, 1985, lk. 495-505.

7 E $9343(24)<\mathrm{Hlj}, 1894$.

8 K. Krohn, Die folkloristische Arbeitsmethode. Oslo, 1926. $167 \mathrm{lk}$.

9 Vt. W. Anderson, Ein volkskundliches Experiment. FFC 141. Helsinki, 1951; W. Anderson, Eine neue Arbeit zur experimentellen Volkskunde. FFC 168. Helsinki. 1956.

${ }^{10} \mathrm{~W}$. Anderson, Studien zur Wortsilbenstatistik der älteren estnischen Volkslieder. Tartu, 1935; A. V. Kõrv, Värsimõõt Veske «Eesti rahvalauludes». ACUT, B XIII : 3. Tartu, 1928.

${ }^{11}$ H. Paukson, Eesti rahvalaulu ettekande rütmist. "Looming" 1930, nr. 4, lk. 433-448.

${ }^{12} \mathrm{~W}$. Anderson, Studien zur Wortsilbenstatistik der älteren estnischen Volkslieder, lk. 193.

${ }^{13}$ W. Anderson, Studien zur Wortsilbenstatistik der älteren estnischen Volkslieder, lk. 193.

${ }^{14}$ O. Lehtipuro, Kalevalaisen runouden tutkimus eilen ja tänään. Kalevala- seuran vuosikirja 54. Porvoo-Helsinki, 1974, lk. 231-242.

${ }^{15}$ P. Leino, Kalevalamitta. - Kalevalamitalla. Helsinki, 1984, lk. 7.

${ }^{16}$ Suomen kirjallisuus I. Kirjoittamaton kirjallisuus. Helsinki, 1963, lk. 130.

${ }^{17}$ O. Loorits, Volkslieder der Liven. Tartu, 1936, lk. XIII.

${ }^{18}$ Vt. M. Kuusi, Kalevalakielen kysymyksiä."Virittäjä” 1978, nr. 3, lk. 215.

${ }^{19}$ P. Alvre, Vepsa regivärsi mõistatus, lk. 11.

${ }^{20}$ P. Alvre, Vepsa regivärsi mõistatus, lk. 12. 
${ }^{21}$ Vt. Eesti rahvalaulud 1:1. Antoloogia, lk. 41-44.

${ }^{22}$ Vt. Eesti uuemad laulumängud I. Koostanud I. Rüütel. Tallinn, 1980, lk. 411-429 (nr. 33 - "Lilla istus vangitornis"),

${ }^{23}$ Vrd. laulunäidet P. Alvre tsiteeritud artiklis lk. 4 ja rekonstruktsioone lk. 7 .

${ }^{24}$ Vt. A. Laanest, Sissejuhatus läänemeresoome keeltesse. Tallinn, 1975. lk. 20, 65-66.

${ }^{25}$ M. Kuusi. Kalevalakielen kvsymyksiä. lk. 223.

${ }^{26}$ M. Kuusi, Kalavalakielen kysymyksiä, lk. 212.

${ }^{27}$ Vt. A. V. Kõrv, Värsimõõt Veske «Eesti rahvalauludes», lk. 15.

${ }^{28}$ Vt. W. Anderson, Studien zur Wortsilbenstatistik der älteren estnischen Volkslieder, lk. 207.

${ }^{29}$ Vt. H. Paukson, Eesti rahvalaulu ettekande rütmist, lk. 446.

${ }^{30}$ P. Leino, Kalevalamitan ongelma. Kalevalaseuran vuosikirja 54, lk. 263.

${ }^{31}$ P. Leino, Kalevalamitan ongelma, lk. 265.

${ }^{32}$ M. Kuusi, Maria Luukan laulut ja loitsut. Mikkeli, 1983, lk, 223. 